\title{
Research Abstract: From Description to Practice
}

\author{
Damian P. Lucantonio \\ University of Electro-Communications
}

The purpose of this paper is to show how university students for whom English is a foreign language can be taught to write an abstract for a research paper. The paper draws on research from Systemic Functional Linguistics, in particular from genre theory (Martin, 1985; Martin \& Rose, 2003; Swales, 1990; 2004; Swales \& Freak, 2004; Freak \& Swales, 2011). A genre-based rating scale is described that makes explicit the specific functions of each section of the abstract. Data from two student abstracts are then analyzed and interpreted, illustrating how the theory has been applied.

Keywords: research, abstract, EFL, explicit, genre, university

\section{INTRODUCTION}

This paper focuses on writing an abstract in English for a research paper. It represents part of broader, ongoing research into writing research papers for postgraduate, EFL science students at the University of Electro-Communications, a national science university in Tokyo, Japan. The paper draws on the theoretical framework of Systemic Functional Linguistics (SFL) (Halliday, 1985; Halliday \& Hasan, 1985) and the design of a genre-based, rating scale for students (Appendix A). The paper also draws on the theoretical background of a previous paper written on this topic (Lucantonio, 2017). However, unlike the previous paper (Lucantonio, 2017), this paper contains new and original research that focuses on student data and on how the theory has been applied. This is illustrated by the analysis of two abstracts written by graduate level, EFL students. Previously (Lucantonio, 2017), no student data was presented or analyzed. In this paper, the student abstracts are analyzed within the concept of genre theory, using the criteria from the rating scale (Appendix A). In addition, an interpretation of the analyses has been provided. Furthermore, the criteria used in the rating scale (Appendix A) have been changed and updated to better reflect the needs of the students.

\section{THEORETICAL BACKGROUND}

The teaching approach taken in this paper to write an abstract is underpinned by the Systemic Functional Linguistics (SFL) theory of language (Halliday, 1985; Halliday \& Hasan, 1985), in particular the concept of genre (Martin, 1985). In addition, the genre-based research of Swales $(1990,2004)$, Swales \& Freak (2004), and Freak \& Swales (2011) in analyzing abstracts and research papers is considered to be of particular importance.

The term genre refers to text types and how different types of texts are organized in different ways to achieve different social purposes (Martin, 1985). Within this theoretical framework, an abstract is 
considered to be a genre. It is argued that, if students for whom English is a foreign or second language are unfamiliar with the sociocultural norms of the genre, then these norms need to be made explicit through the teaching approach (Lucantonio, 2009; 2014; 2017). This is referred to as explicit teaching (Gibbons, 2002; Lucantonio, 2009; 2014; 2017).

According to Martin (1985), a genre can be defined as a staged, goal-oriented, social process. The term 'staged' refers to the steps the text moves through to achieve its goal. Martin (1985) refers to these steps as generic structure and is commonly referred to as the patterning of a text (Lucantonio, 2009; 2014; 2017). The term goal-oriented refers to the purpose of the text. According to Martin \& Rose (2003), texts typically move through certain stages to achieve a goal or to reach a conclusion, and are patterned or organized in different ways to reflect their different social purposes. It is argued that EFL students may not be familiar with the sociocultural norms associated with this patterning. Therefore, they not only need to know what information needs to be included in a research abstract, but also how the information is organized to achieve its goal (Lucantonio, 2009; 2014; 2017). Hence, the specific order in which the information is organized is important. The term social process represents the process of how meanings are created and exchanged in society (Martin \& Rose, 2003). Genres, then, are not a static collection of structures and formulas. According to Eggins \& Slade (1997), they are negotiated interactively in society according to sociocultural norms that have been institutionalized over time, and therefore represent an important social process.

As genres are an interactive social process, they are comprised of both obligatory and optional elements (Halliday \& Hasan, 1985; Eggins \& Slade, 1997). The obligatory elements are those that are recognized as the defining features of the genre and the appearance of these elements in a specific order corresponds to our perception that the text is either complete or incomplete (Eggins \& Slade, 1997). They are likely to occur most of the time (Lucantonio, 2014; 2017). However, optional elements are those that are not necessarily defining features. They can be omitted or added depending on the writer (Lucantonio, 2014; 2017). In teaching the genre of an abstract, it is therefore important to make explicit the elements that are compulsory and the elements that are optional, as well as the specific order in which the elements occur (Lucantonio, 2014; 2017). The issue of compulsory versus optional elements of a genre is important and has been incorporated into the design of the genre-based rating scale.

\section{ANALYZING THE ABSTRACT}

An abstract is a kind of summary of the research paper. However, not all summaries are the same in that different summaries have different social purposes (Martin, 1985; Lucantonio, 2014; 2017). Drawing on genre theory and the work of Swales $(1990,2004)$ and Swales and Feak (2004) in analyzing research papers, six sequentially ordered steps have been identified in the generic structure of research abstracts that are written in English. These steps have been incorporated into the design of the genre-based rating scale. The scale functions as a self-check tool for students, as well as an evaluation instrument that teachers use for grading (Appendix A). In addition to the six steps, three grammar-focused points, considered important for EFL students when writing an abstract, have also been incorporated into the updated design of the rating scale (Appendix A). Step 1 and step 6 of the scale are considered to be optional elements. These are identified by the use of brackets. Step 2 through to step 5 are considered to be compulsory elements. It is argued that these steps and the order in which they occur are necessary for the abstract to achieve its sociocultural goal. They reflect the sociocultural norms of writing an abstract in English. It cannot be assumed that EFL students would necessarily be familiar with the six steps and therefore it is argued that these steps need to be explicitly taught.

\section{THE RATING SCALE}

Based on the above theoretical framework, the following represents a description of and a rationale for the criteria used in the updated version of the rating scale (Appendix A). 
Step 1 of the criteria focuses on the general background information of the research. However, the step is regarded as an optional element and can be omitted (Lucantonio, 2014; 2017). Background information orientates the reader to the 'who, what, where, when and why-type' information of the research paper (Lucantonio, 2009). It introduces the reader to what research has been done in this field or on this topic. Although it is an optional element in an abstract, background information is common in this section. References are often used. As background information affects the current state of the research, information is usually expressed in the present tense.

In step 2 of the criteria, the purpose or aim of the research needs to be clearly stated. This is considered to be an essential element of an abstract (Lucantonio, 2014; 2017). In addition, the research question(s) or hypothesis, if required, can also be stated in this step. The present tense is usually used to state the purpose of the research. Also, the use of the present infinitive is commonly used when stating what the research intends to do or intends to achieve. While stating the purpose of the research is considered to be an essential element of an abstract, it is often problematic for EFL students who struggle to express this clearly.

The next compulsory element refers to the methodology used in the research. This is step 3 of the rating scale. The most important issue here is to describe the steps or the procedure that the research moved through in order to achieve its goal (Lucantonio, 2014; 2017). The past tense is commonly used to do this, as the research procedure has now finished. While the participants and the materials involved in the research may also be referred to here, the main issue is to provide a step-by-step description of how the research was done. Sequential discourse markers are commonly used to explicitly show this, such as 'first', 'following this', 'then', 'next', 'finally', and other such markers that indicate the order in which the procedure was carried out. While this is not considered to be a linguistically complex task, describing how a procedure is carried out is important and needs to be made explicit, as it is often a problematic issue for EFL students.

In step 4, the results of the research need to be briefly stated. This step refers to what the raw data show or showed (Lucantonio, 2014; 2017). Either the present tense or the past tense is commonly used to do this. Brief interpretations on the data are a feature in step 4. These can be shown by the use of text markers, such as: 'As a result ...'; 'As can be seen ...'; 'The results show ...'. These can also be summary statements, illustrating what the results actually mean. Examples of these are statements indicating an increase ('more', 'faster', 'bigger', etc.), or a decrease ('less', 'slower', 'smaller', etc.), or no change ('remains the same', 'no difference' etc.). Statements such as these are often used and are appropriate in this section. The focus here is on describing what the data show or showed, not why the data are important. The importance of the data is addressed in the next section, the conclusion.

In step 5 the conclusions of the research are stated. It involves interpreting the data or findings from the results section in relation to the research purpose (Lucantonio, 2014; 2017). Hence, the conclusions should refer back to the research purpose, indicating whether or not the aim has been successful. As the conclusion is a generalized account of what is learned in the research, the present tense is often used. Text markers that indicate concluding statements such as: 'In conclusion ...'; 'It can be concluded ...'; are a feature in this step. Also, highlighting statements similar to the results section, such as: 'As a result ...'; 'As can be seen ...'; 'The results show ...'; are often used. However, the focus here is not on what the raw data show but rather on interpreting and summing up the main conclusions. In this step, the writer states the degree to which the research has been successful (or not) in achieving its goals.

The final step of the criteria is step 6, in which the contributions of the research to the general field or to the topic area are stated. While this is common in many abstracts, it is considered to be an optional element and can be omitted (Lucantonio, 2014; 2017). The contributions move away from the specific results of the research towards how it adds to the development of the broader field. It states why the findings are important (or not) to the general field, and the degree to which the specific research contributes to more knowledge and more understanding of the general topic or research area. As it is a generalized statement, the present tense is commonly used to do this.

The six steps of the criteria needed for an abstract have been incorporated into the design of the updated rating scale (Appendix A). In addition, information relating to non-personal writing and aspects 
of syntactical grammar have also been added, as well as information relating to the use of text markers. These are used to signal the beginning of each generic section of the abstract, as well as the main points within a particular stage, and can be used either explicitly or implied. The use of text markers is considered an important tool for students. It is a way of making their meanings clear and explicit, a task that is often problematic for EFL students. In summary, the rating scale represents a self-checking, evaluation instrument for students. It makes explicit the kind of information students need to include in an abstract, as well as the order in which the information needs to occur.

\section{RESEARCH VERSUS RESEARCHER}

Drawing on the work of Halliday in SFL (1985), non-personal writing has been identified as an important grammatical feature in the register of formally written, scientific texts. According to Halliday (1985), this allows the reader to focus on the development of the research, rather than focusing on the researcher. The issue of using non-personal versus personal writing is an important issue for students when writing an abstract.

In SFL, the grammatical item of Theme, which roughly equates to the grammatical subject of a sentence, sets up the message of a text (Halliday, 1985). It is through the message that the logical development of a text occurs (Halliday, 1985). In formally written, scientific English, this typically occurs through non-personal writing. Through the use of non-personal items in the subject position of a sentence, the writer is able to focus on the development of the research, rather than the researcher ('I' or ' $\mathrm{We}$ '). Typically, non-personal reference describes what is unfolding in the research, rather than personal reference to those who conducted it - that is, the researcher. Within this theoretical framework, personal reference items in the subject position, such as 'I' or 'we', have little value in the logical development of a scientific text. Hence, the use of non-personal writing is viewed as an important resource for students to acquire when writing a research abstract.

These days many journals, particularly in the field of engineering, accept texts for publication that are written in a more casual register, using elements of personal reference ('I' or 'We'). However, it is argued in this paper that students need to learn how to write in a variety of appropriate registers, both casual and formal. After at least 8 years of English language education at undergraduate and graduate levels (in Japan), it is assumed that students are relatively familiar with the use of personalized reference in the writing process. The same cannot be assumed with non-personal writing. It is important for students to understand that it is not a question of right or wrong, but rather there are differences between personal and non-personal writing, and students should understand the role that non-personal writing plays in the development of scientific and academic texts.

Grammatical reformulation exercises focusing on the subject-verb-object (SVO) sentence structure can be useful in helping students to write in a non-personal register. It is not difficult. Reformulation exercises can be constructed that focus on eliminating the personal subject of a sentence ('I' or 'We') by placing the object in the subject position, and then changing the verb from the active to the passive voice. Exercises such as these explicitly demonstrate to students how personal reference in the subject position can be eliminated and why this is important in the logical development of a scientific text. To illustrate this, the sentence: "I/We measured the speed" could be easily reformulated to: "The speed was measured (by me/us)." Exercises such as these help students recognize that the message of the sentence (that is, the subject) focuses more on the research, rather than the researcher. Thus, the issue of non-personal writing has also been included in the design of the rating scale.

\section{CURRICULUM CYCLE}

The genre-based curriculum cycle used for teaching in this paper has three basic phases. These are modeling, joint negotiation and independent construction (DSP Literacy Project, 1989). The cycle draws on several key concepts from Sociocultural Learning Theory (SCT) (Lantolf, 2000; Lantolf \& Thorne, 2006), in particular, the issue of scaffolding, in which the teacher is required to break down the 
complexity of the task into manageable chunks. According to Gibbons $(2002,2006)$, scaffolding is the temporary assistance by which a teacher helps a learner know how to do something, so that the learner will later be able to complete a similar task alone. It should lead to independent learning (Lucantonio, 2009; 2014; 2017). The construction of an abstract is considered a complex task for EFL learners. However, the complexity level of the task can broken down with different degrees of teacher scaffolding, which can be varied according to the different linguistic abilities of the students (Lucantonio, 2009; 2014; 2017). In this paper, the issue of scaffolding has been incorporated into the design of the rating scale from a linguistic perspective by making the structure of the abstract explicit, and by the way in which relatively simplistic language has been used to explain the meanings of the criteria (Appendix A).

The modeling phase is usually the first stage of the teaching/learning cycle (DSP Literacy Project, 1989). In this phase, a model of the target genre is introduced to the learners. If the learners are to construct a particular genre, they first need to become familiar with its purpose and genre features (Lucantonio, 2009; 2014; 2017). In this phase, the teacher concentrates mainly on making the generic structure or patterning of the abstract explicit to the learners. In pairs, students analyze model texts written by previous students, identifying the generic structure according to the criteria in the rating scale. They identify the main stages of the abstract, focusing on discourse markers, which are used to signal the different stages. Students mark off each stage of the abstract, and then give a rating of 3(Excellent) or 2(So-so) or 1(Poor) for each stage, using the criteria in the rating scale. Once this has been done, attention is then given to the genre's key grammatical features of tense and non-personal writing, as described in the rating scale. Once the analysis of the model abstract has been completed, students are then asked to write their own for homework, again following the criteria in the rating scale. This guides them into the next phase of the pedagogical cycle, the joint negotiation phase.

In the next phase, the joint negotiation phase, the students begin to move away from analyzing model texts, and move towards constructing their own (Lucantonio, 2017). In this phase, students peer evaluate each other's abstracts and rate them according to the criteria in the rating scale. They do this with the assistance of the teacher, moving from group to group around the classroom, checking, assisting, and providing feedback on an as-required basis. In Sociocultural Learning Theory, this is known as the coconstruction of language (Gibbons, 2002, 2006; Lantolf, 2000; Lantolf \& Thorne, 2006). An important feature of the joint negotiation phase is that the teacher scaffolding is being gradually removed (Lucantonio, 2017). Greater responsibility is handed over to the learners for the construction and evaluation of their own text. Following the peer evaluations, the students are then asked to rewrite their drafts again for homework and have them ready to hand in to the teacher in the next class. This leads them into the final phase of the pedagogical cycle, the independent construction phase.

In the independent construction phase, the learners reach the point where the scaffolding is removed. In this phase, learners construct the target genre without assistance from the teacher (DSP Literacy Project, 1989; Lucantonio, 2009; 2014; 2017). In this phase, the practice and preparation are over. It is now time to see how well the students can independently perform the task of writing an abstract, after the modeling and joint negotiation phases have been completed. This represents the final step of the pedagogical cycle. The students' abstracts are collected and then evaluated by the teacher, using the criteria in the rating scale for purposes of grading.

\section{DATA ANALYSES: STUDENT ABSTRACTS}

The data analyses in Table 1 and Table 2 focus on two abstracts written by graduate level, EFL students. Based on the criteria in the rating scale, a rating of 'Excellent' or 'So-so' or 'Poor' has been given by the teacher for each generic stage of the abstract. This is indicated by the mark, ' $\mathrm{X}$ ' (see analyses below). Finally an interpretation of the analyses for each generic stage is given.

Journal of Higher Education Theory and Practice Vol. 20(1) 2020129 


\section{Student Text 1: Digital Curling}

TABLE 1

ANALYSIS OF STUDENT TEXT 1: DIGITAL CURLING

\begin{tabular}{|c|c|c|c|}
\hline $\begin{array}{l}\text { Generic Stages } \\
\text { \& Main Register } \\
\text { Variables }\end{array}$ & $\begin{array}{l}\text { Excellent } \\
\text { Stage clearly } \\
\text { stated/easy to } \\
\text { understand; register } \\
\text { appropriately used }\end{array}$ & $\begin{array}{l}\text { So-So } \\
\text { Stage possibly stated but } \\
\text { not clear/quite difficult } \\
\text { to understand; register } \\
\text { occasionally } \\
\text { inappropriately used }\end{array}$ & $\begin{array}{l}\text { Poor } \\
\text { Stage not stated or very } \\
\text { difficult to understand; } \\
\text { register inappropriately } \\
\text { used }\end{array}$ \\
\hline $\begin{array}{l}\text { (Background Information): } \\
\text { Past/present research in field; } \\
\text { References often used; present } \\
\text { tense }\end{array}$ & $X$ & & \\
\hline $\begin{array}{l}\text { Research Purpose: } \\
\text { Goal or aim of your research; } \\
\text { present tense }\end{array}$ & $X$ & & \\
\hline $\begin{array}{l}\text { Methodology: Procedure or } \\
\text { steps undertaken in your } \\
\text { research; participants/materials } \\
\text { optional; past tense }\end{array}$ & $X$ & & \\
\hline $\begin{array}{l}\text { Results: } \\
\text { What data show(ed); } \\
\text { increase/decrease/no change; } \\
\text { present or past tense }\end{array}$ & $X$ & & \\
\hline $\begin{array}{l}\text { Conclusion: } \\
\text { Main findings; the } \\
\text { extent to which purpose has } \\
\text { been achieved; present tense }\end{array}$ & $X$ & & \\
\hline $\begin{array}{l}\text { (Contributions): Extent to } \\
\text { which your research } \\
\text { conclusions are important for } \\
\text { the field; present tense }\end{array}$ & N/A & & \\
\hline $\begin{array}{l}\text { Use of Text } \\
\text { Markers (Explicit/Implicit) }\end{array}$ & $\mathrm{X}$ (Explicit) & & \\
\hline $\begin{array}{l}\text { Time Reference } \\
\text { / Tense }\end{array}$ & $\mathrm{X}$ & & \\
\hline $\begin{array}{l}\text { Use of Syntactical Grammar } \\
\text { (e.g. S-V-O Agreement) }\end{array}$ & & $\mathrm{X}$ & \\
\hline
\end{tabular}

\section{Interpretation of Text 1: Digital Curling}

From the analysis, the writer of Student Text 1 has displayed many errors of syntactical grammar and limited word choice. However, based on the criteria, the writer has independently constructed a research abstract that is structured appropriately to its social purpose.

In the first paragraph, the writer starts with background information, introducing the reader to the topic of digital curling and to relevant AI research that has been conducted in the field. Various references have been provided. The background has been constructed using the present tense (or present time reference), which is appropriate for an abstract. Rating: Excellent.

In the second paragraph, the writer clearly states the goal or aim of the research is to develop an AI to obtain an approximate action value function for digital curling. The present tense is used. This is followed by a description of the research methodology, explaining how the procedure or steps to conduct the research were undertaken. These are made clear by the explicit and appropriate use of text markers. The 
writer has consistently used the past tense to explain the procedure that was undertaken. Rating: Excellent.

In the third paragraph, the main result is given. The writer has signaled this by the highlighting statement: 'The results show ...'. Furthermore, the writer has used a suitable summary statement to interpret the main result, stating that the greedy policy player is significantly stronger (probably meaning 'better') than the random-shot policy player. This information is appropriate for the results stage. The present tense is used. Rating: Excellent.

In the fourth and final paragraph, three main conclusions are presented. These indicate that the research has successfully developed an AI to obtain an approximate action value function for digital curling. The conclusions relate directly back to the purpose or aim of the research, indicating that the goal has been successfully achieved. The writer has used the present tense to present these conclusions, which is appropriate for the conclusion stage. Rating: Excellent.

The contribution of the research to the general field, or the extent to which the research conclusions are important, is not stated. This is possibly judged to be unimportant or beyond the scope of this abstract. However, as this is considered to be an optional element of an abstract, the omission does not detract from the overall meanings or effectiveness of the abstract. Rating: Not Applicable (N/A).

In terms of grammar, the writer has used explicit text markers appropriately to clearly introduce each generic stage of the text, as well as the steps involved in the research procedure. The time reference used to express each generic stage has been both consistent and appropriate. This has been the present tense for each stage, with the exception of the past tense, which was used to explain the research method used to conduct the research. Rating: Excellent.

Errors of syntactical grammar, focusing on subject-verb-object agreement and word choice, can be found in the text. However, these errors do not significantly impede the overall meanings, as expressed in the generic structure of the abstract. Rating: So-So.

In summary, the writer has independently constructed a research abstract based on the criteria described in the genre-based rating scale (Appendix A). The generic stages that the text moves through are logical, appropriate to the social purpose, and clearly expressed. While there are some errors of accuracy in the writer's use of syntactical grammar and word choice, these do not significantly affect the overall meanings expressed in the abstract. Furthermore, the use of text markers and tense reference are logical, appropriate and clearly expressed. Based on the criteria in the rating scale, the construction of the text is appropriate to the social purpose of a research abstract and, as such, it has been evaluated as being a successful abstract. 


\section{Student Text 2: Film Festivals}

TABLE 2

ANALYSIS OF STUDENT TEXT 2: FILM FESTIVALS

\begin{tabular}{|c|c|c|c|}
\hline $\begin{array}{l}\text { Generic Stages } \\
\text { \& Main Register } \\
\text { Variables }\end{array}$ & $\begin{array}{l}\text { Excellent } \\
\text { Stage clearly stated/easy to } \\
\text { understand; register } \\
\text { appropriately used }\end{array}$ & $\begin{array}{l}\text { So-So } \\
\text { Stage possibly stated but } \\
\text { not clear/quite difficult } \\
\text { to understand; register } \\
\text { occasionally } \\
\text { inappropriately used }\end{array}$ & $\begin{array}{l}\text { Poor } \\
\text { Stage not stated or very } \\
\text { difficult to understand; } \\
\text { register inappropriately } \\
\text { used }\end{array}$ \\
\hline $\begin{array}{l}\text { (Background Information): } \\
\text { Past/present research in field; } \\
\text { References often used; present } \\
\text { tense }\end{array}$ & $X$ & & \\
\hline $\begin{array}{l}\text { Research Purpose: } \\
\text { Goal or aim of your research; } \\
\text { present tense }\end{array}$ & $X$ & & \\
\hline $\begin{array}{l}\text { Methodology: Procedure or } \\
\text { steps undertaken in your } \\
\text { research; participants/ } \\
\text { materials optional past tense }\end{array}$ & & $X$ & \\
\hline $\begin{array}{l}\text { Results: } \\
\text { What data show(ed); } \\
\text { increase/decrease/no change; } \\
\text { present or past tense }\end{array}$ & $X$ & & \\
\hline $\begin{array}{l}\text { Conclusion: } \\
\text { Main findings; the } \\
\text { extent to which purpose has } \\
\text { been achieved; present tense }\end{array}$ & $X$ & & \\
\hline $\begin{array}{l}\text { (Contributions): Extent to } \\
\text { which your research } \\
\text { conclusions are important for } \\
\text { the field; present tense }\end{array}$ & N/A & & \\
\hline $\begin{array}{l}\text { Use of Text } \\
\text { Markers (Explicit/Implicit) }\end{array}$ & & $\begin{array}{l}\text { X } \\
\text { (Explicit for } 2 \text { generic } \\
\text { stages; Implicit for } \\
\text { method \& results) } \\
\end{array}$ & \\
\hline $\begin{array}{l}\text { Time Reference } \\
\text { / Tense }\end{array}$ & $X$ & & \\
\hline $\begin{array}{l}\text { Use of Syntactical Grammar } \\
\text { (e.g. S-V-O Agreement) }\end{array}$ & & $X$ & \\
\hline
\end{tabular}

\section{Interpretation of Text 2: Film Festivals}

From the analysis, the writer of Student Text 2 has independently constructed a research abstract that is structured appropriately to its social purpose.

In the first paragraph, the writer starts with background information, introducing the reader to the topic and role of film festivals, and to the limited research that has been conducted in the field. Due to this, only one reference is provided. Following this, in the last sentence of the first paragraph, the writer clearly states the goal or aim of the research. The background and aim of the research have been constructed using present time reference, all of which is appropriate. Rating: Excellent.

In the second paragraph, the writer states the methodology used in the research. In this stage, the materials and participants involved are presented. However, understanding of the writer's procedure in this stage is sometimes confusing, as elements of methodology appear to be mixed together with elements 
of background information. Also, unlike Student Text 1, the steps undertaken to conduct the research seem to be implied. Text markers are not explicitly used and hence the procedural steps are not made clear. This, leads to a certain degree of confusion on the part of the reader. However, the writer has used the past tense to explain the procedure that was undertaken, which is appropriate to the purpose of the methodology section. Rating: So-So.

In the third paragraph, the main results are given and data is presented to support the claims. The results of both models are presented clearly, using appropriate summary statements, illustrating that random forest was a better model to predict attendance. The past tense is used. Rating: Excellent.

In the fourth and final paragraph, the main conclusions are given. These relate directly back to the research purpose. The findings indicate that while non-linear regression models are better, both models cannot predict attendance with a high degree of accuracy. However, the findings show that features relating to the type of theater are most important for predicting attendance at film festivals. Rating: Excellent.

The contribution of the research to the general field, or the extent to which the research conclusions are important, is not stated and is therefore judged to be unnecessary or beyond the scope of the abstract. This is similar to Student Text 1. However, as this is an optional element, the absence of this element does not detract from the overall effectiveness of the abstract. Rating: Not Applicable (N/A).

The writer has appropriately used explicit text markers to introduce the purpose and conclusion stages of the text. However, unlike Student Text 1, the explicit use of these markers is absent from the method and results stages. The steps involved in the research procedure are not explicitly signaled due to the absence of text markers. Hence, the reader's understanding of the procedure is unclear and the transition from the method to the results stage is also unclear to a certain degree. As a result, the absence of text markers affects the reader's understanding of these two sections. Rating: So-So.

The time reference used to express each generic stage has been both consistent and appropriate. This has been the use of the present tense for the background, purpose and conclusion stages, and the past tense for the method and results stages. Rating: Excellent.

As with Student Text 1, various errors of syntactical grammar and word choice can be found in the text. However, it is judged that these errors do not significantly impede the overall meanings expressed in the construction of the abstract. Rating: So-So.

In conclusion, the writer has independently constructed a research abstract based on the criteria described in the rating scale (Appendix A). The generic stages that the text moves through are logical and appropriate to the social purpose. The generic stages are explicitly expressed in the background, purpose and conclusion sections, and implicitly stated in the method and results sections. There are some errors of accuracy in the writer's use of syntactical grammar. However, these do not significantly impede the overall meanings expressed in the abstract. In summary, based on the criteria in the rating scale, the construction of the text is appropriate to the social purpose of a research abstract and, as such, is evaluated as being satisfactory.

\section{CONCLUSION}

The two abstracts analyzed in this paper are considered to be typical of the abstracts produced by students in this course. It is argued that a genre-based approach can help students write an abstract in a way considered to be appropriate to its social purpose. While the two student abstracts are far from perfect in terms of syntactical grammar, the meanings they convey are logical, and are organized in a way that is understandable and suitable to the sociocultural norms of an abstract. By making the criteria explicit through a genre-based rating scale, students can understand what information needs to be included and how the information needs to be arranged. This is useful for students from an EFL or ESL background, who may not be familiar with the sociocultural norms of writing an abstract in English. Through the use of the genre-based pedagogical cycle of modeling-joint negotiation-independent construction, students can initially become familiar with the genre features, and then use that knowledge to co-construct their own draft of the genre, with peer group conferencing and teacher support. Finally, the scaffolding can be removed and they can independently write their own. By incorporating issues of 
scaffolding in the pedagogical cycle, the teacher can break down the complexity of the task into manageable chunks. By making the criteria explicit and using an appropriate pedagogical cycle, the complex task of writing an abstract can be unpacked and demystified for learners (Lucantonio, 2009; 2014; 2017). This is empowering for all students, particularly those from a foreign or second language background.

The issues raised in the paper seek to make contributions to research into linguistics and language education. Firstly, the importance of merging linguistic theory to pedagogical practice is illustrated. This stresses the importance of basing teaching practices on informed theories of language, rather than intuitive or anecdotal views (Lucantonio, 2018). It is also argued that if learners are required to construct different types of texts, such as a research abstract, then it is important for teachers to know how texts 'work' and how texts are organized to achieve their social purposes. To this end, professional knowledge of and skills in a text-based, linguistic theory, such as genre theory, can be useful for teachers when assisting students to achieve their language goals (Lucantonio, 2018).

\section{REFERENCES}

DSP Literacy Project. (1989). A brief introduction to genre. Sydney, Australia: Metropolitan East Region, NSW Department of Education.

Eggins, S., \& Slade, D. (1997). Analyzing casual conversation. London, UK: Cassell.

Freak, C. B., \& Swales, J. M. (2011). Creating contexts: Writing introductions across genres. Ann Arbor, MI: University of Michigan Press.

Gibbons, P. (2002). Scaffolding language, scaffolding learning. Portsmouth, NH: Heinemann.

Gibbons, P. (2006). Bridging discourses in the ESL classroom: Students, teachers and researchers. London, UK: Continuum.

Halliday, M. A. K. (1985). An introduction to functional grammar. London, UK: Edward Arnold.

Halliday, M. A. K., \& Hasan, R. (1985). Language, context and text: Aspects of language in a social semiotic perspective. Geelong, Australia: Deakin University Press.

Lantolf, J. P. (Ed.). (2000). Sociocultural theory and second language learning. Oxford, UK: Oxford University Press.

Lantolf, J. P., \& Thorne, S. L. (2006). Sociocultural theory and the genesis of second language development. Oxford, UK: Oxford University Press.

Lucantonio, D. (2009). Developing casual conversation skills of pre-school children learning English as a foreign language in the home context. (Unpublished doctoral dissertation). University of Technology, Sydney, Australia.

Lucantonio, D. (2014). Teaching the research paper. In M. Pinto \& D. Shaffer (Eds.), The Proceedings of the $201321^{\text {st }}$ Korea TESOL International Conference. Seoul, Republic of Korea: Korean TESOL. 177-186.

Lucantonio, D. (2017). Writing an abstract: A genre-based approach. In M. Pinto \& D. Shaffer (Eds.), The Proceedings of the 2016 23rd Korea TESOL International Conference. Seoul: Korea TESOL. 173-180.

Lucantonio, D. (2018, September). Developing conversation skills through storytelling genres. International Journal of Languages, Literature, and Linguistics, 4(3), 188-197.

Martin, J. R. (1985). Factual writing: Exploring and challenging social reality. Geelong, Australia: Deakin University Press.

Martin, J. R., \& Rose, D. (2003). Working with discourse: Meaning beyond the clause. London, UK: Continuum.

Swales, J. M. (1990). Genre analysis: English in academic and research settings. Cambridge, UK: Cambridge University Press.

Swales, J. M. (2004). Research genres: Explorations and applications. Cambridge, UK: Cambridge University Press.

Swales, J. M., \& Freak, C. B. (2004). Academic writing for graduate students: Essential tasks and skills. Ann Arbor, MI: University of Michigan Press.

134 Journal of Higher Education Theory and Practice Vol. 20(1) 2020 


\section{APPENDIX A: A GENRE-BASED RATING SCALE FOR THE RESEARCH ABSTRACT}

Key:

( ) = Optional element

3 Points: Excellent. Clearly stated \&/or well expressed (easy to understand)

2 Points: So-so. Possibly stated but not clear (quite difficult to understand)

1 Point: Poor. Not stated \&/or poorly expressed (very difficult to understand)

(*Step 1:) States the background information: What research has been done in this area from the past leading up to the present situation; references sometimes used; 'wh-' information; present tense.

Excellent (3)

So-so (2)

Poor (1)

*Step 2: States the purpose of the research: What is the aim or goal of your research;(state the research question/hypothesis); present tense.

\begin{tabular}{lcc} 
Excellent (3) So-so (2) & Poor (1) \\
\hline
\end{tabular}

*Step 3: States the method used in the research: How your research was done; the procedure or steps used (also participants \& materials); past tense.

Excellent (3)

So-so (2)

Poor (1)

*Step 4: States the results: describes What the raw data show(ed); (increase/decrease/no change, more/less, stronger/weaker, higher/lower/remains the same, etc.; past or present tense.

Excellent (3)

So-so (2)

Poor (1)

*Step 5: States the conclusions: States the main conclusions; to what extent was the purpose or goal achieved (successful or not); present tense.

Excellent (3)

So-so (2)

Poor (1)

(*Step 6:) States the contributions of the research: To what extent are your conclusions important for the general research area; present tense.

\begin{tabular}{|c|c|c|}
\hline Excellent (3) & So-so (2) & Poor (1) \\
\hline \multicolumn{3}{|c|}{ *Can use suitable text markers to introduce each stage } \\
\hline Excellent (3) & So-so (2) & Poor (1) \\
\hline \multicolumn{3}{|c|}{ *Can focus on research (non-personal) > researcher (personal: I/we) } \\
\hline Excellent (3) & So-so (2) & Poor (1) \\
\hline \multicolumn{3}{|c|}{ *Can use grammar accurately and appropriately (S-V-O). } \\
\hline Excellent (3) & So-so (2) & Poor (1) \\
\hline
\end{tabular}

